Virginia Commonwealth University VCU Scholars Compass

2014

\title{
A metagenomic assessment of the bacteria associated with Lucilia sericata and Lucilia cuprina (Diptera: Calliphoridae)
}

Baneshwar Singh

Virginia Commonwealth University, bsingh@vcu.edu

Tawni L. Crippen

Southern Plains Agricultural Research Center, Agricultural Research Service, USDA

Longyu Zheng

Texas AઐM University

See next page for additional authors

Follow this and additional works at: https://scholarscompass.vcu.edu/frsc_pubs

Part of the Microbiology Commons

(C) Springer-Verlag Berlin Heidelberg 2014

Downloaded from

https://scholarscompass.vcu.edu/frsc_pubs/3

This Article is brought to you for free and open access by the Dept. of Forensic Science at VCU Scholars Compass. It has been accepted for inclusion in Forensic Science Publications by an authorized administrator of VCU Scholars Compass. For more information, please contact libcompass@vcu.edu. 


\section{Authors}

Baneshwar Singh, Tawni L. Crippen, Longyu Zheng, Andrew T. Fields, Ziniu Yu, Qun Ma, Thomas K. Wood, Scot E. Dowd, Micah Flores, Jeffery K. Tomberlin, and Aaron M. Tarone 


\section{Lucilia cuprina (Diptera: Calliphoridae).}

3 Baneshwar Singh ${ }^{1,2,10}$, Tawni L. Crippen ${ }^{3}$, Longyu Zheng ${ }^{1,3,4}$, Andrew T. Fields ${ }^{1,5}$, Ziniu

$4 \mathrm{Yu}^{4}$, Qun $\mathrm{Ma}^{6}$, Thomas K. Wood ${ }^{7}$, Scot E. Dowd ${ }^{8}$, Micah Flores ${ }^{1,9}$, and Jeffery K.

5 Tomberlin $^{1}$, Aaron M. Tarone ${ }^{1}$

6

${ }^{1}$ Department of Entomology, Texas A\&M University, College Station, TX, ${ }^{2}$ Department of Forensic Science, Virginia Commonwealth University, Richmond, VA, ${ }^{3}$ Southern Plains Agricultural Research Center, Agricultural Research Service, USDA, College Station, $\mathrm{TX}^{4}$ State Key Laboratory of Agricultural Microbiology, National Engineering Research Center of Microbe Pesticide, Huazhong Agricultural University, China, , ${ }^{5}$ School of Marine and Atmospheric Sciences, Stony Brook University, Stony Brook, NY, ${ }^{6}$ Tianjin Institute of Industrial Biotechnology, Chinese Academy of Science, Tianjin, China, ${ }^{7}$ Department of Chemical Engineering, The Pennsylvania State University, University Park, PA, ${ }^{8}$ MR DNA Molecular Research LP, Shallowater TX, ${ }^{9}$ Walter Reed Army Institute of Research, Silver Spring, MD, ${ }^{10}$ Corresponsing author.

\section{Corresponding author:}

Name: Baneshwar Singh

Address: Department of Forensic Science, Virginia Commonwealth University, 1015

Floyd Avenue, Richmond, VA 23284

Email: bsingh@vcu.edu

Phone \#: +1-804-828-9576

Fax \#: +1-804-828-4983

Citation: Singh B, Crippen T, Zheng L, Fields A, Yu Z, et al. 2015. A metagenomic assessment of the bacteria associated with Lucilia sericata and Lucilia cuprina (Diptera: Calliphoridae). Appl. Microbiol. Biotechnol. 99: 869-83 
Abstract

Lucilia Robineau-Desvoidy (Diptera: Calliphoridae) is a blow fly genus of forensic, medical, veterinary, and agricultural importance. This genus is also famous because of its beneficial uses in maggot debridement therapy (MDT). Although the genus is of considerable economic importance, our knowledge about microbes associated with these flies, and how these bacteria are horizontally and trans-generationally transmitted is limited. In this study, we characterized bacteria associated with different life stages of Lucilia sericata (Meigen) and Lucilia cuprina (Wiedemann) and in the salivary gland of L. sericata by using $16 \mathrm{~S}$ rDNA 454-pyrosequencing. Bacteria associated with salivary gland of $L$. sericata were also characterized using light and transmission electron microscopy (TEM). Results from this study suggest that the majority of bacteria associated with these flies belong to phyla Proteobacteria, Firmicutes, and Bacteroidetes, and most bacteria are maintained intra-generationally, with a considerable degree of turnover from generation to generation. In both species, second generation eggs exhibited the highest bacterial phylum diversity ( $20 \%$ genetic distance) than other life stages. The Lucilia sister species shared the majority of their classified genera. Of the shared bacterial genera Providencia, Ignatzschineria, Lactobacillus, Lactococcus, Vagococcus, Morganella, and Myroides were present at relatively high abundances. Lactobacillus, Proteus, Diaphorobacter, and Morganella were dominant bacterial genera associated with a survey of the salivary gland of $L$. sericata. TEM analysis showed sparse distribution of both Gram-positive and Gram-negative bacteria in the salivary gland of $L$. sericata. There was more evidence for horizontal transmission of bacteria than there was for trans-generational inheritance. Several pathogenic genera were either amplified or reduced by the larval feeding on decomposing liver as a resource. Overall, this study provides information on bacterial communities associated with different life stages of Lucilia, and their horizontal and trans-generational transmission, which may help in development of better vector-borne disease management and MDT methods.

37 Keywords: Microbial community, blow flies, maggot debridement therapy, salivary 
gland, 454-sequencing.

2

3

4 Introduction

Improved biological knowledge of species from the blow fly (Diptera:

Calliphoridae) genus Lucilia Robineau-Desvoidy, especially the sister species L. sericata (Meigen) and L. cuprina (Wiedemann), benefits basic (Singh and Wells 2013), medical (Greenberg 1973; Sherman 2009; Sherman et al. 2000; Sherman and Pechter 1988), veterinary (Stevens and Wall 1996), and forensic science endeavors (Anderson 2000; Grassberger and Reiter 2001; Sze et al. 2012; Tarone 2007; Tarone and Foran 2008; Tarone et al. 2007; Tarone et al. 2011). Since these species are primary colonizers of carrion, developmental data from these species can be useful for predicting the ages of immature blow flies associated with a body, which can help in estimating a minimum time of colonization for death investigations (Amendt et al. 2007; Tomberlin et al. 2011). They also serve as a mechanical vector of pathogens (Fischer et al. 2004; Maldonado and Centeno 2003), and are at the center of numerous neglect law suits related to the abuse of dependents, companion animals, and livestock (Hall 2005). Some species are also responsible for transmission of antibiotic resistant bacterial strains (Liu et al. 2013; Wei et al. 2014a; Zurek and Ghosh 2014).

Both species engage in myiasis, larval infestation of animal tissues (Ashworth and Wall 1994), which causes more than $\$ 150$ million USD of annual economic loss to the wool industry in Australia alone (Department of Agriculture and Food, Australia). This behavior has beneficial uses though, as certain L. sericata strains (LB-01) are useful in maggot debridement therapy (MDT) (Mumcuoglu 2001; Sherman 2009). This practice uses sterilized larvae and their preference for dead tissue to debride non-healing necrotic wounds more efficiently than a surgeon or associated treatments (van der Plas et al. 2009). Given that the adults and larvae of the genus feed on feces and carrion (Clark et al. 2006) and live in constant association with decomposing matter, it is not surprising that their larval excretions and secretions (ES) have been demonstrated to possess antimicrobial properties (Cazander et al. 2009a; Harris et al. 2009; Kerridge et al. 2005; Mumcuoglu et al. 2001; Sherman et al. 2000). Larval ES has also recently been 
1 implicated in the ability to manipulate the development of microbial biofilms (Cazander

2 et al. 2009b; Cazander et al. 2010; Harris et al. 2009) and to stimulate wound angiogenesis (Bexfield et al. 2010), which may explain some of their antimicrobial and bio-surgical value. Accordingly, knowledge of microbial community associated with

5 these flies can help ameliorate the negative perception of the approach (Steenvoorde et al. 2005) and promote their beneficial properties. investigated. Insect-microbe interactions are well documented (Hilker and Meiners 2002;

In all of the examples listed above, there is a likely microbial role that could be Ma et al. 2012b; Schröder and Hilker 2008). Microbial communities can affect lifehistory traits (Ma et al. 2012a), and sex ratios (Hurst and Jiggins 2000), which can both influence the survival of a population. Microbes can also influence attraction of insects to their hosts (Hilker and Meiners 2002). For instance, Proteus mirabilis attracts L. sericata (Ma et al. 2012b; Tomberlin et al. 2012); Musca domestica Linnaeus (Diptera: Muscidae) females have been shown to prefer to oviposit on eggs coated with certain Gram-positive bacteria (Lam et al. 2007), and Aedes aegypti (Linnaeus) (Diptera: Culicidae) prefer oviposition on mixture of 14 bacteria isolates from bamboo leaf-infusion compared to water as a control (Ponnusamy et al. 2008). Since bacteria and their associated metabolites can influence blow fly behavior, it seems likely that bacterial research with these flies will have repercussions for forensic, medical, veterinary, and agricultural applications (Tomberlin et al. 2012).

Identifying the potential microbial contaminants of experiments is important for deciphering the variation observed in research observed with these species. While maggot debridement therapy has been shown to decrease the prevalence of some microbes on a wound, other microbes are unaffected or increase in prevalence in association with treatment with L. sericata larvae (Jaklic et al. 2008). Sterile techniques for rearing Lucilia sericata are well established (Mumcuoglu et al. 2001; Sherman and Tran 1994) but in some situations (e.g., use of non-sterile maggots instead of sterile maggots) MDT can also cause septicemia (Mumcuoglu 2001). In some situations more than two species can colonize a wound pre-mortem, which can complicate calculation of minimum postmortem interval estimation when using insect evidence in death investigations (Sanford et al. 2014). In all of these cases, knowledge of microbes associated with non- 
1 sterile larvae would aid in 1) identifying the likely sources of septicemia in the case of

2 failed maggot debridement therapy, 2) interpreting the results of potentially non-sterile

3 ES experiments, 3) identifying bacteria that are unaffected by the feeding of Lucilia

4 larvae, and 4) identify bacteria that attract different blow flies for oviposition pre- or post-

5 mortem.

$6 \quad$ These considerations raise several questions regarding potential bacterial

7 communities associated with these important blow flies: 1) What bacteria are associated

8 with these species, and how similar are the bacterial communities associated with each

9 species?; 2) What bacteria are likely to be trans-generationally transmitted and what

10 bacteria are likely to be horizontally transmitted?; and 3) What bacteria are amplified or

11 eliminated by larval feeding? To address these questions, we conducted a survey of

12 bacterial communities associated with these sister species using 16S rDNA 454-

13 pyrosequencing.

14 Materials and Methods

15 Fly colony maintenance

16 Lucilia sericata were collected from Davis, CA, USA in 2006 and maintained as

17 previously described (Tarone and Foran 2008). The transcriptome of this strain is

18 published (Sze et al. 2012). Lucilia cuprina were collected from the "Miracle Mile" neighborhood and University of Southern California campus in Los Angeles, CA, USA in 2007 (Li et al. 2014) and maintained in the same conditions as L. sericata. Both species

21 were identified by both morphological and molecular methods using identification keys as previously described (Tarone and Foran 2006; Tarone and Foran 2008; Whitworth

23 2006).

\section{Sample collection}

Fly life stages

Generationally related eggs, larvae, pupae and adults (male and female) were raised in the same environment on raw beef liver. Each of the experiments was done with one replicate per species, as the goal was to 1) categorize bacteria associated with the flies and 2) determine if it appeared likely that bacteria were mostly horizontally or trans-

30 generationally inherited. Approximately $0.5 \mathrm{~g}$ eggs ( $\left(1^{\text {st }}\right.$ generation eggs or G1 egg) were 
1 harvested sequentially as the flies developed. The resulting $3^{\text {rd }}$ instar larvae (Larva),

2 pupae (Pupa), adult males (AM), adult females (AF), and $2^{\text {nd }}$ generation eggs (G2egg)

3 were randomly collected and frozen at $-80^{\circ} \mathrm{C}$ until DNA extraction could be performed.

$4 \quad$ Salivary gland removal protocol

5 Because L. sericata larvae exhibit special salivary gland chemistry important in

6 maggot debridement therapy, we also surveyed bacteria associated with the salivary gland

7 of L. sericata third instar larva. L. sericata from a separate cohort was raised at room

8 temperature on beef liver. Feeding third instars with full crops were collected with

9 forceps and transferred in a non-sterile plastic cup to the dissection area. Maggots were

10 washed in a $1.25 \%$ sodium hypochlorite solution followed by two washes in sterile

11 phosphate buffered saline (PBS). Salivary glands were dissected with sterile forceps

12 under a stereomicroscope and placed in sterile PBS on ice. This process was repeated

13 thrice to obtain a concentration of one salivary gland per $10 \mathrm{~mL}$ of PBS (one pair of

14 salivary glands per $20 \mathrm{~mL}$ ) was achieved. The extracted salivary glands were either

15 collected for transmission electron microscopy (TEM) or homogenized with a sterile

16 Teflon pestle and were used for DNA extraction and 454-pyrosequencing. For the TEM

17 experiment, crops from the same individuals were also collected and analyzed as a

18 positive control for the presence of bacteria.

19 Transmission electron microscopy

20 Salivary glands were preserved in a fixative consisting of $3 \%$ glutaraldehyde, $2 \%$ 21 paraformaldehyde and $12 \%$ picric acid prepared in $50 \mathrm{mM}$ phosphate buffer, $\mathrm{pH} 7.4$, and

$2250 \mathrm{mM}$ sucrose. Salivary glands in fixative were incubated at room temperature for 60

$23 \mathrm{~min}$. then held at $4^{\circ} \mathrm{C}$. Subsequent to primary fixation, salivary glands were postfixed for

$242 \mathrm{hr}$. at $4^{\circ} \mathrm{C}$ in $1 \%$ osmium tetroxide prepared in $100 \mathrm{mM}$ phosphate buffer, $\mathrm{pH} 7.4$, $100 \mathrm{mM}$ sucrose and $50 \mathrm{mM} \mathrm{K}_{4} \mathrm{Fe}(\mathrm{CN})_{6}$ (potassium ferricyanide). After osmication,

26 samples were rinsed at $4^{\circ} \mathrm{C}$ in $50 \mathrm{mM}$ phosphate buffer, $\mathrm{pH} 7.4$, containing $50 \mathrm{mM}$

27 sucrose followed by eight rinses in $4^{\circ} \mathrm{C}$ distilled $\mathrm{H}_{2} \mathrm{O}$ over the course of $2 \mathrm{hr}$, then post-

28 staining overnight at $4{ }^{\circ} \mathrm{C}$ in $0.5 \%$ uranyl acetate. Following post-staining, samples were

29 rinsed in $4{ }^{\circ} \mathrm{C}$ distilled $\mathrm{H}_{2} \mathrm{O}$ and dehydrated in a graded ethanol series, and acetone.

30 Dehydration was followed by infiltration and embedding in Mollenhauer's formulation of

31 epoxy resin (Mollenhauer 1964). Thin TEM sections, $70 \mathrm{~nm}$, were cut and stained using 
$11 \%$ uranyl acetate and lead citrate then viewed in a Hitachi $\mathrm{H} 7000$ transmission electron

2 microscope. Sections $750 \mathrm{~nm}$, for light microscopy were stained with either $0.05 \%$

3 toluidine blue or a mixture of basic fuchsin and toluidine blue (Multiple Stain,

4 Polysciences, Warrington, PA, USA).

5 Determining the proportion of bacteria that are horizontally and trans-generationally

6 inherited

To better understand the dynamics of bacterial exchange between the environment and $L$. sericata, an experiment was conducted to allow adult flies to oviposit on three different commercial sources of liver (previously frozen at $-20^{\circ} \mathrm{C}$ ) and follow the flies that developed (Fig. S1). The bacteria from the adults and liver prior to oviposition and from $3^{\text {rd }}$ instars and the liver after development were evaluated. The three liver sources were collected from different supply chains $(\mathrm{x}, \mathrm{y}$, and $\mathrm{z})$ to maximize the variation in liver-associated microbes. Four $0.25 \mathrm{~g}$ replicate samples were randomly collected from each liver sample prior to exposure to adult flies (fresh liver) and after use by and removal of flies (aged liver). Four replicate samples each of 6 ( 3 male and 3 female) adult flies prior to access to the liver (adult) and of $0.25 \mathrm{~g} 3^{\text {rd }}$ instar larvae that were oviposited and had grown on the specific liver sources (larvae) were randomly collected. Samples were stored at $-80^{\circ} \mathrm{C}$ until DNA extraction was performed. The experiment was replicated three times.

\section{DNA extraction}

DNA extractions were performed from $0.25 \mathrm{~g}$ liver tissue, $0.25 \mathrm{~g}$ eggs ( 1 hour old), two larvae (7-day old), two pupae, and two newly emerged adults. These samples were selected randomly and whole insect specimens were homogenized in $1.5 \mathrm{ml}$ PBS. Briefly, homogenized samples were placed in $1.5 \mathrm{ml}$ microcentrifuge tubes with $500 \mu 1$ Tris-EDTA (pH=8), $50 \mu 1$ 10\% SDS, $3 \mu 1$ proteinase $\mathrm{K}(20 \mathrm{mg} / \mathrm{ml}), 1.5 \mu 1$ of lysozyme $(50 \mathrm{mg} / \mathrm{ml})$ and then incubated with shaking $(900 \mathrm{rpm})$ at $56^{\circ} \mathrm{C}$ in a water bath. After 1 hour of incubation, $100 \mu \mathrm{l} \mathrm{NaCl}(5 \mathrm{M})$ and $80 \mu \mathrm{CTAB}$ extraction solution (Teknova, USA) were added and samples thoroughly mixed and incubated at $65^{\circ} \mathrm{C}$ for 10 minutes.

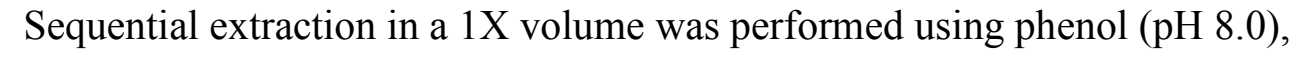
phenol/chloroform/isoamyl alcohol (25:24:1), and chloroform/isoamyl alcohol (24:1) by centrifugation at $6000 \mathrm{x}$ g for 6 minutes. The DNA was precipitated in 0.7 volume of 
1 isopropanol, washed twice in $70 \%$ ethanol, dissolved in nuclease free water, and

2 quantified by spectrophotometry. Extracted DNA was aliquotted and sent to Research and

3 Testing Laboratory (http://www.researchandtesting.com/) for 16S rDNA 454-

4 pyrosequecning using universal bacterial primer pair $27 \mathrm{~F}\left(5^{\prime}-\right.$

5 GAGTTTGATCNTGGCTCAG) and 519R (5'- GTNTTACNGCGGCKGCTG) by

6 bacterial tag-encoded FLX-Titanium pyrosequencing (bTEFAP) method (Dowd et al.

7 2008) in Genome Sequencer FLX System (Roche, Nutley, NJ, USA). All FLX related

8 procedures were performed following Genome Sequencer FLX System manufacturers

9 instructions (Roche, Nutley, NJ, USA).

10 Pyrosequencing data analysis

11 Sequences with lengths less than $150 \mathrm{bp}$ were removed and remaining sequences

12 (103629) were checked for chimera formation using web based chimera check program

13 Decipher (Wright et al. 2012) (http://decipher.cee.wisc.edu/FindChimeras.html) (accessed

14 on April 19, 2012). Suspected chimeric sequences (6461) were deleted from the dataset

15 and only chimera free sequences (97168) were used for further analyses. Hierarchical

16 classification of the 97168 16S rDNA sequences were carried out according to the

17 Bergey's bacterial taxonomy (Garrity et al. 2004) using Naïve Bayesian rRNA classifier

18 version 2.2 (Wang, et al., 2007) as implemented in Ribosomal Database Project (RDP)

19 Multiclassifier version 1.0. Only sequences having $\geq 80 \%$ bootstrap support were

20 considered classified at a particular hierarchical level. Venn diagram of all classified

21 sequences were created using software Vennture (Martin et al. 2012)

Heat map graphics were generated by using gplots package in $\mathrm{R}$ version 2.13.0 ( $\mathrm{R}$ Development Core Team 2006) for all genera that were present at $\geq 0.5$ percent relative sequence abundance. For better visualization $\%$ relative sequence abundance values were natural $\log$ transformed before its use in the heat map. The $0 \%$ values were converted into $0.01 \%$ for $\log$ transformation. Bacterial genera were clustered based on rooted $\mathrm{NJ}$ tree (Yaxis) (See below for detail) whereas fly life stages and bacterial sources were clustered based on FastUniFrac based clustering (X-axis) which helps in better comparison of bacteria by phenotypic and taxonomic characteristics important to bacterial community functional analysis.

Duplicate and nearly duplicate sequence from each data set (L. sericata including 
salivary gland data, L. cuprina and bacterial sources) were removed using default parameters in CD-HIT 454 (Niu et al. 2010), and only unique sequences ( $<98 \%$ sequence similarity) from each data sets were used for the construction of neighbor-joining (NJ) trees. NJ trees were rooted based on 16S rRNA gene sequence of Thermatoga maritima (M21774) and Aquifex pyrophilus (M83548). For NJ tree construction all data sets were aligned based on 16S rRNA secondary structure in Infernal aligner (Nawrocki and Eddy 2007; Nawrocki et al. 2009), as implemented in the Ribosomal Database Project (RDP) under tool Aligner (http://rdp.cme.msu.edu/) (accessed on October 22, 2012). Hypervariable ambiguous regions were manually deleted from the multiple sequence alignment in MEGA5 (Tamura et al. 2011). Evolutionary distances of aligned sequences were calculated by NJ method with the Kimura two-parameter correction (Saitou and Nei 1987) for 1000 bootstrap replications in PAUP* v.4.0b10 (Swofford 2003). Calculated evolutionary distances were used for construction of rooted NJ trees in PAUP* v.4.0b10 (Swofford 2003).

Approximate maximum-likelihood trees were constructed from all sequences (including outgroups Thermatoga maritima (M21774) and Aquifex pyrophilus (M83548) 16S rDNA sequences) of each data set using default parameters in FastTree2 (Price et al. 2010). Approximate ML trees were used as an input file in FastUniFrac based clustering of bacterial communities (Hamady et al. 2009) associated with different samples. Jackknifing with 1000 permutations was performed for node support of the FastUniFrac tree. $P$-tests were performed using 1000 permutations for each pair of samples and for all samples together in FastUniFrac (Hamady et al. 2009). All trees were edited using Archaeoptryx version 0.957 beta (Han and Zmasek 2009) and FigTree v1.3.1 (http://tree.bio.ed.ac.uk/).

Diversity indices were calculated using tools available in RDP pyrosequencing pipeline (http://pyro.cme.msu.edu/). Rarefaction curves were generated in Excel 2007 (Microsoft Corporation, Redmond, WA) using results obtained from the tools aligner, complete linkage clustering, and rarefaction of RDP pyrosequencing pipeline (Cole et al. 2009) (http://pyro.cme.msu.edu/; accessed on October 23, 2012). Shannon (1948) and Chaol (2002) indices were calculated using tool Shannon and Chaol index of RDP pyrosequencing pipeline (Cole et al. 2009) (http://pyro.cme.msu.edu/; accessed on 
1 October 23, 2012). Percentage coverage of species richness was calculated from

2 rarefaction and Chaol indices using method as described in Zheng et al. (2013). All raw

3 sequence files were submitted to Sequence Read Archive (SRA). Study accession \#

4 PRJEB6623 can be used for the retrieval of raw sequences used in this study.

5 Results

6 General characteristics of 454 -sequences

8 length of $296 \mathrm{bp}$. These samples came from successive life stages of the blow fly sister

9 species L. cuprina and L. sericata. The number of sequences obtained from first

10 generation eggs (G1 egg), larvae, pupae, male adults (AM), female adults (AF) and

11 second generation eggs (G2egg) samples were 1965, 1961, 3081, 2415, 4451, 234 in $L$.

12 cuprina and 3053, 4113, 1752, 2583, 3896, 288 in L. sericata, respectively. In L. cuprina,

13 approximately $99.7 \%, 98.8 \%, 98.1 \%, 92.7 \%$, and $82 \%$ of all sequences were classified

14 with $\geq 80.0 \%$ bootstrap support into 5 phyla, 11 classes, 17 orders, 42 families, and 59

15 genera, respectively. On the other hand, in L. sericata approximately $99.9 \%, 99.7 \%$, $99.4 \%, 98.2$ and $76.5 \%$ of all sequences were classified with $\geq 80.0 \%$ bootstrap support into 7 phyla, 13 classes, 22 orders, 49 families, and 83 genera, respectively. Additionally

$181283,13347,22790,17261$, and 12695 sequences were also obtained from L. sericata salivary gland, $L$. sericata adults, $L$. sericata third instar larvae, fresh liver, and aged liver

respectively (see Fig. S1 for experimental design). In these samples, approximately $99.6 \%, 99.5 \%, 97.9 \%, 94.8 \%$, and $77.0 \%$ of all sequences (respectively) were classified with $\geq 80.0 \%$ bootstrap support into 6 phyla, 11 classes, 20 orders, 38 families, and 47 genera, respectively.

\section{Taxonomic distribution of 454-sequences}

The majority of sequences ( $>99 \%$ ) collected from successive life stages of Lucilia belonged to the phyla Proteobacteria, Firmicutes, and Bacteroidetes (Fig. 1; Table S1). Phylum level relative sequence abundances associated with male and female adult $L$. sericata flies were almost the same (mainly Proteobacteria), but this was not true with $L$. cuprina male and female adults (Fig. 1; Table S1). Acidobacteria and Actinobacteria were mainly associated with second-generation eggs (G2egg) in both species. Fusobacteria was mainly present in L. sericata second-generation eggs (G2egg) samples. 
1 Similarly, more than $90 \%$ of all classified sequences across all life stages belong to the

2 classes Gammaproteobacteria, Bacilli, and Flavobacteria and orders Enterobacteriales,

3 Xanthomonadales, and Lactobacillales in both Lucilia species (Table S1). Additionally,

$4 \quad$ Flavobacteriales and Bacillales were present at relatively higher sequence abundances in

5 pupal samples of both Lucilia species. At the family level, Enterobacteriaceae,

6 Xanthomonadaceae, Lactobacillaceae, and Enterococcaceae were present in high

7 numbers across all life stages of Lucilia spp. (Table S1). Flavobacteriaceae were mainly

8 present in the pupal stage of both Lucilia species (Table S1). Although the blow fly sister

9 species shared the majority of their classified genera (42 genera), there were some that

10 were only observed in one species (Fig. 2). Of the bacterial genera identified

11 Lactobacillus (25\%), Providencia (24\%), Ignatzschineria (10\%), Lactococcus (8\%) and

12 Vagococcus (4.4\%) were the five most dominant genera associated with L. cuprina,

13 whereas Providencia (53\%), Ignatzschineria (5\%), Myroides (4\%), Lactobacillus (3\%),

14 and Morganella (2.6\%) were the five most dominant genera associated with L. sericata

15 (Fig. 3; Table S1). Pupae of both blow fly species had relatively high abundances of

16 Myroides.

17 In both species, a FastUniFrac based $P$-test suggests that bacterial communities

18 differ significantly between life stages $(p \leq 0.001)$ and bacterial communities associated

19 with each of the life stages are significantly clustered $(p \leq 0.001)$. An unweighted

20 FastUniFrac based tree, which is based on composition (and not quantity) of bacteria

21 associated with each sample, shows similar clustering pattern between life stages in both

22 blow fly species. In both species the adult female shares more bacterial taxa with G1egg,

23 than to either the adult male or any other life stages. Similarly, the larval stage shares

24 more bacterial taxa with pupae, than to any other life stages. In both species, the G2egg

25 stage shared the least number of bacteria with other life stages (Fig. 3) and yielded the

26 least numbers of sequences. Relationships between different life stage samples were not

27 the same in L. sericata and L. cuprina in a weighted FastUniFrac based tree (Fig. S2a \& 28 b).

29 Bacterial richness and diversity indices

30 In L. cuprina, bacterial diversity at species (3\% sequence divergence) and genus

31 (5\% sequence divergence) levels was similar in all life stages, but at the phylum level 
1 (20\% genetic divergence), diversity was relatively higher in G2egg than any other life

2 stages (Table 1). In L. sericata, at species (3\% sequence divergence) and genus (5\%

3 sequence divergence) levels, bacterial diversity was almost same in all life stages, except

4 in male adult samples, where bacterial diversity was lowest compared to all other life

5 stage samples at all sequence divergences. At $20 \%$ sequence divergence, bacterial

6 diversity was relatively higher in G2egg and pupal samples. Similar trends were observed

7 with rarefaction and Chao1 estimators (Table 1, Fig. S3). Sequencing effort covered more

8 than $60 \%$ of bacterial diversity at species level (except $L$. sericata pupa), more than $66 \%$

9 at genus level (except G2egg in L. cuprina, and pupal samples in L. sericata), and more

10 than $80 \%$ at phylum level (except Glegg and pupa in L. cuprina).

11 Bacteria in the salivary glands of $\boldsymbol{L}$. sericata

Bacteria in the salivary glands of $L$. sericata were assessed using two different techniques: pyrosequencing and microscopy. Based on sequencing results, the two most

14 dominant phyla, classes, orders, and families associated with the $L$. sericata salivary

15 gland were Firmicutes (52.1\%) and Proteobacteria (41.9\%), Bacilli (44.1\%) and Gammaproteobacteria (28.7\%), Lactobacillales (41.5\%) and Enterobacteriales (27.1\%), and Enterobacteriaceae (27.1) and Lactobacillaceae (22.0\%), respectively. The salivary

18 gland community structure was more similar to G2egg than to any other life stages of $L$. sericata (p-value $<0.001$ ) (Fig. 3b). Among classified bacterial genera, more than $60 \%$ of the sequences belonged to the genera Lactobacillus, Proteus, Diaphorobacter, and Morganella in decreasing order in the salivary gland of L. sericata (Fig. 4). The salivary glands were also evaluated by TEM, using a comparison to crops (Fig. 5). Crops were bacterial cells were sparse in the salivary glands. Only a few bacterial cells were found in the salivary gland after evaluation of numerous slices from 20 maggots, but this is partially due to the delicate structure of the gland making sectioning a challenge. Structures indicative of both Gram-positive and Gram-negative cells were located within the salivary duct, supporting the sequencing observations (Fig. 5).

\section{Trans-generationally and horizontally transmitted bacteria}

Bacterial communities associated with fresh liver and aged liver samples were more similar to each other than to either $L$. sericata adults that landed, ate, and oviposited 
on the liver or the L. sericata larvae that had fed upon the liver in both weighted and

2 unweighted FastUniFrac based clustering (Fig. S4). Adult and aged liver samples shared

312 bacterial genera that were not present in larval and fresh liver samples. On the other

4 hand, L. sericata adult and larval samples did not share any bacteria that were not present

5 in other samples. Total 15 genera were shared by all samples (adult, larva, fresh liver, and

6 aged liver). Out of 15 genera, Proteus, Enterococcus, and Lactobacillus were the

7 dominant genera that were present in all samples (Fig. 6a \& 6b). Several pathogenic

8 genera were also present in adult and/or fresh liver samples, which either got amplified or

9 reduced by larval activities (Fig. 7).

\section{Discussion}

11 This study was designed to evaluate the bacterial communities associated with

12 two sister Lucilia species (L. sericata and L. cuprina), which are important to medicine,

13 agriculture, veterinary, and forensic science. The work was designed to ask which

14 bacteria are associated with each species and how similar are their respective bacterial

15 communities, which bacteria are horizontally or trans-generationally transmitted, and

16 which are amplified or eliminated during larval feeding

17 The first part of the study evaluated an un-replicated (at the level of fly species)

18 developmental time series of fly-associated bacterial communities, starting with eggs,

19 proceeding throughout development, and culminating in a second generation of eggs.

20 These data are useful for establishing the presence of certain members of the bacterial

21 communities, but absence and concentration information should be carefully considered

22 with the fact that replication was not done per time point per species. With this caveat in

23 mind, it is interesting to note that many of the same bacteria appeared in both time series,

24 it was clear that there was a different community composition associated with species,

25 representing numerous taxa, mostly from those phyla found in the human (Backhed et al.

26 2005) and insect (Gupta et al. 2012; Gupta et al. 2014; Wei et al. 2014b; Zheng et al.

27 2013) gut. Relative abundances appeared to differ between species, but this portion of the

28 study was not replicated within species, making it impossible to differentiate replicate

29 effects from species effects. Given that limitation, both time series observations still

30 demonstrated that each sister species of Lucilia consists of some putatively unique and

31 many shared bacterial genera, with a large turnover in community occurring for both 
species at oviposition.

Among shared bacterial genera, Providencia and Ignatzschineria were present in relatively high abundance in the sister species of Lucilia. These genera were also observed with several other carrion-breeding flies (Gupta et al. 2012; Gupta et al. 2014; Wei et al. 2014b; Zheng et al. 2013), and hence it looks like they are typical bacterial genera of carrion breeding flies. Providencia produces several Xylanases, and helps in decomposition of xylan, which is commonly observed at decomposition sites (Raj et al. 2013). Ignatzschineria is strong in chitinase activity, and its high abundances in larval and pupal samples suggest that it may be playing a significant role in insect metamorphosis (Toth et al. 2001). Although Lactobacillus was shared by both Lucilia species, its relative abundance was comparatively higher in L. cuprina than in L. sericata. Lactobacillus is also commonly observed at decomposition sites, and is known to inhibit growth of many harmful bacteria by making environment acidic. Similarly, Myroides (Flavobacteriaceae) was present at comparatively high abundance in pupal samples, which most probably protect pupa from harmful environmental bacteria, because Myroides produces bio-surfactants with known antibacterial properties (Dharne et al. 2008; Spiteller et al. 2000).

At the commencement of a new generation, bacterial communities associated with eggs were considerably altered from the previous generation, even from that of the maternal bacterial communities. Trans-generationally inherited bacteria in G2egg might have come either from the mother or from environment. In both Lucilia species, G2egg samples differed from other life stages mainly because of relatively high abundance of Acidobacteria and Actinobacteria (Fig. 1). The genome of Acidobacteria contains several cellulose and protein synthesizing genes (Ward et al. 2009). A network of bacterial celluloses can produce biofilm, retain water under dry conditions, and helps in aeration. All these functions of the network of celluloses most probably contribute in egg structure and protection of eggs from desiccation (Ward et al. 2009). Members of Actinobacteria are known to produce several antimicrobial bioactive compounds, which may be protecting egg from harmful bacteria and fungi (Mahajan and Balachandran 2012; Raghava Rao et al. 2012). This may also be a reason why we see relatively less bacterial sequences in egg samples compared to other life stage samples. This was seen previously 
in the black soldier fly, Hermetia illucens (L.) (Diptera: Stratiomyidae) (Zheng et al.

2 2013), and it remains to be seen if this is a property of the experimental design or a

3 feature of carrion fly biology. Fusobacteria, which is a causative agent for bacteremia,

4 was observed only in the G2egg of L. sericata, which suggests to us that these bacteria

5 may be the responsible agent for the fatal myiasis, sometimes caused by L. sericata

6 (Henry et al. 1983; Mowlavi et al. 2011).

7 The results of these initial observations would indicate that many of the bacteria

8 associated with carrion flies are acquired from the environment. This has implications for

9 the management of pathogen transmitted by these insects and could explain a proportion

10 of the variation measured in the development of these flies on different resources. It

11 should also be noted that, within a generation, many of the same taxa were observed at

12 multiple life stages, suggesting that replication of experiments is more important between

13 generations than within. This also suggests that, once oviposition has occurred, larvae

14 (and subsequent) life history stages retain many of the microbes in their community.

15 Thus, there may be high selective pressures on maternal choice of potential larval

16 resources driven by the bacteria present, particularly if any of those bacteria have fitness

17 effects on flies. This also indicates a need for larval plasticity with respect to adapting to

18 the variation in bacterial community structure on larval resources, since even

19 communities found on the same resource type may vary considerably.

To specifically address whether bacterial communities were trans-generationally or horizontally inherited, a set of replicated observations were made using L. sericata. associated with $L$. sericata adults was more similar to fresh and aged liver samples than to larval sample, whereas in weighted FastUniFrac clustering, bacterial community

30 structures associated with fresh and aged liver samples was more similar to larval 31 samples than to adult samples (Fig. S4). Because weighted FastUniFrac clustering is 
1 based both on bacterial composition and quantity (compared to just bacterial composition

2 in unweighted FastUniFrac clustering), a close relationship between liver and larval

3 samples in weighted FastUniFrac clustering is most probably because of similar numbers

4 and types of taxa in these samples, suggesting convergence in communities due either to

5 larval manipulation of the bacterial community on the liver or the ability of larvae to

6 persist in the community found on the liver without needing to regulate its own

7 community. For example, Vagococcus and Lactobacillus were present at very high \%

8 relative abundances ( $>25 \%)$ in larval and liver samples, but their relative abundances

9 were significantly low $(<1 \%)$ in adult samples.

10 Many bacterial genera are common throughout the system (e.g. Proteus,

11 Lactobacillus, and Enterococcus) and their source (fly versus liver) could not be

12 distinguished. These are likely very important bacteria to the system and may be

13 symbionts of Lucilia. For instance, Proteus, which is attractive to Lucilia, is found in

14 commensal relationship with Lucilia, and is not well eliminated by maggot debridement

15 therapy (Fleischmann 2004; Nigam et al. 2006). This species is also known to produce

16 "mirabilicides", which kill some of the same bacteria $L$. sericata eliminates in maggot

17 debridement therapy (Greenberg 1968; Mumcuoglu et al. 2001). For this reason, Proteus

18 has been suggested as a potential means to enhance maggot debridement therapy.

Second, there was much more evidence for horizontal transmission of bacteria than there was for taxa that were trans-generationally inherited. Many bacterial genera

21 (including Staphylococcus) are shared only by adult and aged liver samples, which suggest that these bacteria could have been deposited on the liver by the adult flies, and did not get completely consumed/eliminated by $L$. sericata larvae. This may be either

24 because the maggots did not get enough feeding time to eliminate the bacteria or the maggots were not effective against these bacteria. This is important from a maggot debridement therapy point of view because if wounds are infected with these bacteria then most maggot treatment will not work on these wounds unless paired with other treatments like antibiotics. Such observations may support published literature on the

29 effectiveness of maggot treatment of wound infections with the famous superbug

30 Methicillin Resistant Staphylococcus aureus (MRSA), which are conflicting and inconclusive (Arora et al. 2011; Mumcuoglu 2001; van der Plas et al. 2008). One 
1 possibility is that the larvae are capable of breaking down and disrupting biofilm

2 formation by MRSA but prevent multiplication of planktonic bacteria and do not kill

3 them (Cazander et al. 2013). Several genera are shared by adult and larval samples, and

4 hence can be considered as potential trans-generationally inherited bacteria but it is not

5 conclusive in this study because these genera are not exclusive to adult and larval

6 samples. Further studies with labeled samples of this genus (as well as the ubiquitous

7 genera) may provide further support for the inheritance patterns of these bacteria, as well

8 as their spread into the environment by the flies.

Third, there appeared to be bacterial "winners" and "losers" in the experiment.

10 There were several taxa that increased in abundance on the aged livers, even as they

11 exhibited low abundances in the adult, larval and fresh liver samples (Fig. 7). These taxa

12 included pathogens, suggesting that larval feeding on decomposition of liver as a

13 resource may amplify the abundances of these microbes. For example, Salmonella was

14 present at significantly low relative abundance $(0.01 \%)$ in fresh liver sample but larval

15 activities increased its relative abundance to significantly high level (2.01\%) in aged liver

16 sample. These observations suggest that these taxa are also not good candidates for

17 removal by maggot debridement therapy, which is at odds with previously published

18 reports that suggest that MDT is effective in controlling several drug resistant pathogens

19 (e.g. Salmonella, Pseudomonas aeruginosa, Escherichia coli, Staphylococcus aureus

20 etc.) but often not Gram-negative bacteria (Cazander et al. 2013; Mumcuoglu 2001).

21 However, there were also some taxa that were almost absent from larvae and aged livers

22 (such as Clostridium sensu stricto). These are likely negatively impacted by the presence

23 of larvae and their bacterial associates, as is observed with Gram-positives, and are better

24 candidates for removal by bio-debridement than those that appear to be amplified in the

25 presence of larvae (Fig. $6 \mathrm{~b}$ and 7). These results suggest a need to match MDT to the

26 situations that are most likely to result in successful wound debridement.

27 As a final experiment, given the importance of larval excretions to maggot

28 therapy, the bacterial communities of the L. sericata salivary gland were evaluated. This

29 yielded several interesting results. First, the microscopic assessment suggests that the

30 salivary gland appears to be an inhospitable environment for bacteria, yielding few cells.

31 Not surprisingly, the bacterial community of this organ appeared to differ from whole 
carcass communities, most strikingly in the fact that Proteus appear in much higher abundances in the salivary gland. The taxa ubiquitously found in all life stages also appeared in the salivary gland, suggesting a possible role of this organ in the maintenance of some bacteria in the fly. In addition, there appears to be a balance between lactic acid producing Gram-positive and urease producing Gram-negative taxa in the salivary gland. It would be interesting to see if either or both routes of metabolism are important to the maintenance of these bacteria in the fly and if an imbalance between these metabolic groups yields negative consequences for the fly.

The overall goal of this research was to evaluate the bacterial communities associated with Lucilia species and to begin to characterize their inheritance patterns. The results of the study indicate that these flies harbor many of the bacterial taxa associated with the human gut and that most bacteria are maintained intra-generationally, with a considerable degree of turnover from generation to generation. There is little evidence in metagenomic analyses to support trans-generational inheritance of blow fly bacterial communities, though there is evidence that larvae appear to regulate their bacterial environment, resulting in bacterial "winners" and "losers" when maggots are present on a resource; some of which are pathogens. This study utilized 454-pyrosequecning approaches to highlight general trend in pathogen transmission by blow flies, but for more accurate individual pathogen transmission pattern, an qPCR based approach will be the best. Future studies should also focus on more detailed egg experiments from several generations of blow flies for elucidation of the mechanism behind vertical transmission of bacteria in blow flies.

\section{Acknowledgements}

The authors would like to thank Dr. Robert Droleskey for his assistance with transmission electron microscopy of salivary gland. Funding for B.S., A.M.T., L.Z., A.T.F., M.F. and J.K.T. was provided partially by Texas Agrilife Research and the College of Agriculture and Life Sciences at Texas A\&M University, College Station, TX. Additional funding for B.S., A.M.T., T.L.C., and J.K.T. was provided by the National Institute of Justice, Office of Justice Programs, U.S. Department of Justice through Grant 2010-DN-BX-K243. B.S. was also supported by start up fund from College of Humanities and Sciences of Virginia 
Commonwealth University, Richmond, VA. We also thank anonymous reviewers for their suggestions that improved this article substantially. Points of view in this document are those of the authors and do not necessarily represent the official position or policies of the U.S. Department of Justice, Department of the Army, Department of Defense or U.S.

5 Government. Mention of trade names, companies, or commercial products in this publication is solely for the purpose of providing specific information and does not imply recommendation or endorsement of the products by the U.S. Department of Agriculture.

Conflict of Interest The authors have no conflict of interest.

\section{References}

Amendt J, Campobasso CP, Gaudry E, Reiter C, LeBlanc HN, Hall MJ, Entomology EAFE (2007) Best practice in forensic entomology--standards and guidelines Int J Legal Med 121:90-104

Anderson GS (2000) Minimum and maximum development rates of some forensically important Calliphoridae (Diptera) J Forensic Sci 45:824-832

Arora S, Baptista C, Lim CS (2011) Maggot metabolites and their combinatory effects with antibiotic on Staphylococcus aureus Ann Clin Microb Anti 10 doi:10.1186/1476-0711-10-6

Ashworth JR, Wall R (1994) Responses of the sheep blowflies Lucilia sericata and L. cuprina to odour and the development of semiochemical baits Med Vet Entomol 8:303-309

Backhed F, Ley RE, Sonnenburg JL, Peterson DA, Gordon JI (2005) Host-bacterial mutualism in the human intestine Science 307:1915-1920

Bexfield A, Bond AE, Morgan C, Wagstaff J, Newton RP, Ratcliffe NA, Dudley E, Nigam Y (2010) Amino acid derivatives from Lucilia sericata excretions/secretions may contribute to the beneficial effects of maggot therapy via increased angiogenesis Br J Dermatol 162:554-562

Cazander G, Pritchard DI, Nigam Y, Jung W, Nibbering PH (2013) Multiple actions of Lucilia sericata larvae in hard-to-heal wounds: Larval secretions contain molecules that accelerate wound healing, reduce chronic inflammation and inhibit bacterial infection Bioessays 35:1083-1092

Cazander G, van Veen KE, Bernards AT, Jukema GN (2009a) Do maggots have an influence on bacterial growth? A study on the susceptibility of strains of six different bacterial species to maggots of Lucilia sericata and their excretions/secretions J Tissue Viability 18:80-87

Cazander G, van Veen KE, Bouwman LH, Bernards AT, Jukema GN (2009b) The influence of maggot excretions on PAO1 biofilm formation on different biomaterials Clin Orthop Relat Res 467:536545

Cazander G, Veerdonk M, Vandenbroucke-Grauls CJE, Schreurs MJ, Jukema G (2010) Maggot excretions inhibit biofilm formation on biomaterials Clin Orthop Relat Res 468:2789-2796

Chao A, Bunge J (2002) Estimating the number of species in a stochastic abundance model Biometrics 58:531-539

Clark K, Evans L, Wall R (2006) Growth rates of the blowfly, Lucilia sericata, on different body tissues Forensic Sci Int 156:145-149

Cole JR, Wang Q, Cardenas E (2009) The ribosomal database project: improved alignments and new tools for rRNA analysis Nucleic Acids Res 37:D141-145

Dharne MS, Gupta AK, Rangrez AY, Ghate HV, Patole MS, Shouche YS (2008) Antibacterial activities of multi drug resistant Myroides odoratimimus bacteria isolated from adult flesh flies (Diptera: sarcophagidae) are independent of metallo beta-lactamase gene Braz J Microbiol 39:397-404 bacterial diversity in the feces of cattle using 16S rDNA bacterial tag-encoded FLX amplicon 
pyrosequencing (bTEFAP) BMC Microbiol 8:125

Fischer OA, Matlova L, Dvorska L, Svastova P, Bartl J, Weston RT, Pavlik I (2004) Blowflies Calliphora vicina and Lucilia sericata as passive vectors of Mycobacterium avium subsp. avium, M. a. paratuberculosis and M. a. hominissuis Med Vet Entomol 18:116-122

Fleischmann W (2004) Maggot Debridement. In: Téot L, Banwell P, Ziegler U (eds) Surgery in Wounds. Springer Berlin Heidelberg, pp 125-128. doi:10.1007/978-3-642-59307-9_13

Garrity G, Bell J, Lilburn T (2004) Bergey's Manual of Systematic Bacteriology. 2nd edn. Springer-Verlag, New York

Grassberger M, Reiter C (2001) Effect of temperature on Lucilia sericata (Diptera: Calliphoridae) development with special reference to the isomegalen- and isomorphen-diagram Forensic Sci Int 120:32-36

Greenberg B (1968) Model for destruction of bacteria in the midgut of blow fly maggots J Med Entomol $5: 31-38$

Greenberg B (1973) Biology and Disease Transmission vol Volume 2. Flies and Disease. Princeton University Press, Princeton, New Jersey

Gupta AK, Nayduch D, Verma P, Shah B, Ghate HV, Patole MS, Shouche YS (2012) Phylogenetic characterization of bacteria in the gut of house flies (Musca domestica L.) FEMS Microbiol Ecol 79:581-593

Gupta AK, Rastogi G, Nayduch D, Sawant SS, Bhonde RR, Shouche YS (2014) Molecular phylogenetic profiling of gut-associated bacteria in larvae and adults of flesh flies Med Vet Entomol doi: $10.1111 /$ mve. 12054

Hall RD (2005) Entomology and the Law-Flies as Forensic Indicators J Med Entomol 42:922-922

Hamady M, Lozupone C, Knight R (2009) Fast UniFrac: facilitating high-throughput phylogenetic analyses of microbial communities including analysis of pyrosequencing and PhyloChip data ISME J 4:1727 doi:http://www.nature.com/ismej/journal/v4/n1/suppinfo/ismej200997s1.html

Han M, Zmasek C (2009) PhyloXML: XML for evolutionary biology and comparative genomics BMC Bioinformatics 10:356

Harris LG, Bexfield A, Nigam Y, Rohde H, Ratcliffe NA, Mack D (2009) Disruption of Staphylococcus epidermidis biofilms by medicinal maggot Lucilia sericata excretions/secretions Int J Artif Organs 32:555-564

Henry S, DeMaria Jr A, McCabe WR (1983) Bacteremia due to Fusobacterium species The American Journal of Medicine 75:225-231

Hilker M, Meiners T (2002) Chemoecology of insect eggs and egg deposition. Blackwell Publishing, Berlin, Germany

Hurst GD, Jiggins FM (2000) Male-killing bacteria in insects: mechanisms, incidence, and implications Emerg Infect Dis 6:329-336

Jaklic D, Lapanje A, Zupancic K, Smrke D, Gunde-Cimerman N (2008) Selective antimicrobial activity of maggots against pathogenic bacteria J Med Microbiol 57:617-625

Kerridge A, Lappin-Scott H, Stevens JR (2005) Antibacterial properties of larval secretions of the blowfly, Lucilia sericata Med Vet Entomol 19:333-337

Lam K, Babor D, Duthie B, Babor EM, Moore M, Gries G (2007) Proliferating bacterial symbionts on house fly eggs affect oviposition behaviour of adult flies Anim Behav 74:81-92

Li F, Wantuch HA, Linger RJ, Belikoff EJ, Scott MJ (2014) Transgenic sexing system for genetic control of the Australian sheep blow fly Lucilia cuprina Insect Biochem Mol Biol doi:10.1016/j.ibmb.2014.06.001

Liu Y, Yang Y, Zhao F, Fan X, Zhong W, Qiao D, Cao Y (2013) Multi-drug resistant Gram-negative enteric bacteria isolated from flies at Chengdu airport, China Southeast Asian J Trop Med Public Health 44:988-996

Ma J, Benson AK, Kachman SD, Hu Z, Harshman LG (2012a) Drosophila melanogaster selection for survival of Bacillus cereus infection: Life history trait indirect responses Int J Evol Biol 2012:935970 doi:10.1155/2012/935970

Ma Q, Fonseca A, Liu W, Fields AT, Pimsler ML, Spindola AF, Tarone AM, Crippen TL, Tomberlin JK, Wood TK (2012b) Proteus mirabilis interkingdom swarming signals attract blow flies The ISME Journal 6:1356-1366

Mahajan GB, Balachandran L (2012) Antibacterial agents from actinomycetes - a review Front Biosci (Elite Ed) 4:240-253 
Maldonado MA, Centeno N (2003) Quantifying the potential pathogens transmission of the blowflies (Diptera: Calliphoridae) Mem Inst Oswaldo Cruz 98:213-216

Martin B, Chadwick W, Yi T, Park SS, Lu D, Ni B, Gadkaree S, Farhang K, Becker KG, Maudsley S (2012) VENNTURE--a novel Venn diagram investigational tool for multiple pharmacological dataset analysis PLoS ONE 7:e36911 doi:10.1371/journal.pone.0036911PONE-D-11-21759 [pii]

Mollenhauer HH (1964) Plastic embedding mixtures for use in electron-microscopy Stain Technol:111-114

Mowlavi G, Nateghpour M, Teimoori S, Amin A, Noohi F, Kargar F (2011) Fatal nosocomial myiasis caused by Lucilia sericata J Hosp Infect 78:338-339

Mumcuoglu KY (2001) Clinical applications for maggots in wound care Am J Clin Dermatol 2:219-227

Mumcuoglu KY, Miller J, Mumcuoglu M, Friger M, Tarshis M (2001) Destruction of Bacteria in the Digestive Tract of the Maggot of Lucilia sericata (Diptera: Calliphoridae) J Med Entomol 38:161-166

Nawrocki E, Eddy S (2007) Query-dependent banding (QDB) for faster RNA similarity searches PLOS Comput Biol 3:0540-0554

Nawrocki E, Kolbe D, Eddy S (2009) Infernal 1.0: inference of RNA alignments Bioinformatics 25:13351337

Nigam Y, Bexfield A, Thomas S, Ratcliffe NA (2006) Maggot therapy: the science and implication for CAM part II-maggots combat infection Evidence-based complementary and alternative medicine : eCAM 3:303-308 doi:10.1093/ecam/nel022

Niu BF, Fu LM, Sun SL, Li WZ (2010) Artificial and natural duplicates in pyrosequencing reads of metagenomic data BMC Bioinformatics 11:187 Doi 10.1186/1471-2105-11-187

Ponnusamy L, Xu N, Nojima S, Wesson DM, Schal C, Apperson CS (2008) Identification of bacteria and bacteria-associated chemical cues that mediate oviposition site preferences by Aedes aegypti Proc Natl Acad Sci U S A 105:9262-9267

Price MN, Dehal PS, Arkin AP (2010) FastTree 2 - Approximately Maximum-Likelihood Trees for Large Alignments PLoS ONE 5:e9490 doi:10.1371/journal.pone.0009490

R Development Core Team (2006) R: A Language and Environment for Statistical Computing. R Foundation for Statistical Computing, Vienna

Raghava Rao KV, Siva Kumar K, Rao DB, Raghava Rao T (2012) Isolation and characterization of antagonistic actinobacteria from mangrove soil J Biochem Technol 3:361-365

Raj A, Kumar S, Singh SK, Kumar M (2013) Characterization of a new Providencia sp. Strain X1 producing multiple xylanases on wheat bran ScientificWorldJournal doi:10.1155/2013/386769

Saitou N, Nei M (1987) The neighbor-joining method: a new method for reconstructing phylogenetic trees Mol Biol Evol 4:406-425

Sanford MR, Whitworth TL, Phatak DR (2014) Human wound colonization by Lucilia eximia and Chrysomya rufifacies (Diptera: Calliphoridae): myiasis, perimortem, or postmortem colonization? J Med Entomol 51:716-719

Schröder R, Hilker M (2008) The relevance of background odor in resource location by insects: A behavioral approach BioScience 58:308-316

Shannon CE (1948) A mathematical theory of communication Bell System Technical Journal 27:379-423

Sherman OA, Tran JMT (1994) A simple, sterile food source for rearing the larvae of Lucilia sericata (Diptera: Calliphoridae) Med Vet Entomol 9:393-398

Sherman RA (2009) Maggot therapy takes us back to the future of wound care: new and improved maggot therapy for the 21 st century J Diabetes Sci Technol 3:336-344

Sherman RA, Hall MJ, Thomas S (2000) Medicinal maggots: an ancient remedy for some contemporary afflictions Annu Rev Entomol 45:55-81

Sherman RA, Pechter EA (1988) Maggot therapy: a review of the therapeutic applications of fly larvae in human medicine, especially for treating osteomyelitis Med Vet Entomol 2:225-230

Singh B, Wells JD (2013) Molecular Systematics of the Calliphoridae (Diptera: Oestroidea): Evidence From One Mitochondrial and Three Nuclear Genes J Med Entomol 50:15-23

Spiteller D, Dettner K, Boland W (2000) Gut bacteria may be involved in interactions between plants, herbivores and their predators: microbial biosynthesis of $\mathrm{N}$-acylglutamine surfactants as elicitors of plant volatiles Biol Chem 381:755-762

Steenvoorde P, Buddingh TJ, van Engeland A, Oskam J (2005) Maggot therapy and the "yuk" factor: an issue for the patient? Wound repair and regeneration : official publication of the Wound Healing Society [and] the European Tissue Repair Society 13:350-352 doi:10.1111/j.1067- 
1927.2005.130319.x

Stevens J, Wall R (1996) Species, sub-species and hybrid populations of the blowflies Lucilia cuprina and Lucilia sericata (Diptera:Calliphoridae) Proc Biol Sci 263:1335-1341 doi:10.1098/rspb.1996.0196

Swofford D (2003) PAUP*: Phylogenetic Analysis Using Parsimony (*and other methods), Version 4 edn. Sinauer Associates, Sunderland, Massachusetts

Sze SH, Dunham JP, Carey B, Chang PL, Li F, Edman RM, Fjeldsted C, Scott MJ, Nuzhdin SV, Tarone AM (2012) A de novo transcriptome assembly of Lucilia sericata (Diptera: Calliphoridae) with predicted alternative splices, single nucleotide polymorphisms and transcript expression estimates Insect Mol Biol 21:205-221

Tamura K, Peterson D, Peterson N, Stecher G, Nei M, Kumar S (2011) MEGA5: Molecular evolutionary genetics analysis using maximum likelihood, evolutionary distance, and maximum parsimony methods Mol Biol Evol 28:2731-2739

Tarone AM (2007) Lucilia Sericata development: Plasticity, population differences, and gene expression. Michigan State University

Tarone AM, Foran DR (2006) Components of developmental plasticity in a Michigan population of Lucilia sericata (Diptera: Calliphoridae) J Med Entomol 43:1023-1033

Tarone AM, Foran DR (2008) Generalized additive models and Lucilia sericata growth: Assessing confidence intervals and error rates in forensic entomology J Forensic Sci 53:942-948

Tarone AM, Jennings KC, Foran DR (2007) Aging blow fly eggs using gene expression: A feasibility study J Forensic Sci 52:1350-1354

Tarone AM, Picard CJ, Spiegleman C, Foran DR (2011) Population and temperature effects on Lucilia sericata (Diptera: Calliphoridae) body size and minimum development time. J Med Entomol 48:1062-1068

Tomberlin JK, Crippen TL, Tarone AM, Singh B, Adams Kelsey, Rezenom YH, Benbow ME, Flores M, Longnecker M, Pechal JL, Russel DH, Beier RC, Wood TK (2012) Interkingdom responses of flies to bacteria mediated by fly physiology and bacterial quorum sensing Anim Behav 84:14491456

Tomberlin JK, Mohr R, Benbow ME, Tarone AM, VanLaerhoven S (2011) A roadmap for bridging basic and applied research in forensic entomology Annu Rev Entomol 56:401-421

Toth E, Kovacs G, Schumann P, Kovacs AL, Steiner U, Halbritter A, Marialigeti K (2001) Schineria larvae gen. nov., sp. nov., isolated from the 1st and 2nd larval stages of Wohlfahrtia magnifica (Diptera: Sarcophagidae) Int J Syst Evol Microbiol 51:401-407

van der Plas MJ, Baldry M, van Dissel JT, Jukema GN, Nibbering PH (2009) Maggot secretions suppress pro-inflammatory responses of human monocytes through elevation of cyclic AMP Diab tologia 52:1962-1970

van der Plas MJ, Jukema GN, Wai SW, Dogterom-Ballering HC, Lagendijk EL, van Gulpen C, van Dissel JT, Bloemberg GV, Nibbering PH (2008) Maggot excretions/secretions are differentially effective against biofilms of Staphylococcus aureus and Pseudomonas aeruginosa J Antimicrob Chemother 61:117-122

Ward NL, Challacombe JF, Janssen PH, Henrissat B, Coutinho PM, Wu M, Xie G, Haft DH, Sait M, Badger J, Barabote RD, Bradley B, Brettin TS, Brinkac LM, Bruce D, Creasy T, Daugherty SC, Davidsen TM, DeBoy RT, Detter JC, Dodson RJ, Durkin AS, Ganapathy A, Gwinn-Giglio M, Han CS, Khouri H, Kiss H, Kothari SP, Madupu R, Nelson KE, Nelson WC, Paulsen I, Penn K, Ren Q, Rosovitz MJ, Selengut JD, Shrivastava S, Sullivan SA, Tapia R, Thompson LS, Watkins KL, Yang Q, Yu C, Zafar N, Zhou L, Kuske CR (2009) Three genomes from the phylum Acidobacteria provide insight into the lifestyles of these microorganisms in soils Appl Environ Microbiol 75:2046-2056

Wei T, Miyanaga K, Tanji Y (2014a) Persistence of antibiotic-resistant and-sensitive Proteus mirabilis strains in the digestive tract of the housefly (Musca domestica) and green bottle flies (Calliphoridae) Appl Microbiol Biotechnol 98:8357-8366

Wei T, Ishida R, Miyanaga K, Tanji Y (2014b) Seasonal variations in bacterial communities and antibioticresistant strains associated with green bottle flies (Diptera: Calliphoridae) Appl Microbiol Biotechnol 98:4197-4208

Whitworth T (2006) Keys to the genera and species of blow flies (Diptera : Calliphoridae) of America North of Mexico Proceedings of the Entomological Society of Washington 108:689-725 
1 Wright ES, Yilmaz LS, Noguera DR (2012) DECIPHER, a Search-Based Approach to Chimera

2 Identification for 16S rRNA Sequences Appl Environ Microbiol 78:717-725

3 Zheng L, Crippen TL, Singh B, Tarone AM, Dowd S, Yu Z, Wood TK, Tomberlin JK (2013) A survey of

4 bacterial diversity from successive life stages of black soldier fly (Diptera: Stratiomyidae) by

$5 \quad$ using 16S rDNA pyrosequencing J Med Entomol 50:647-658

6 Zurek L, Ghosh A (2014) Insect represent a link between food animal farms and the urban environment for

7 antibiotic resistent trait Appl Environ Microbiol 80:3562-3567 
Table 1 Table showing bacterial diversity, evenness, and \% coverage at three genetic distances.

\begin{tabular}{|c|c|c|c|c|c|c|c|c|c|c|c|c|c|c|c|c|}
\hline \multirow[t]{2}{*}{ Species } & \multirow[t]{2}{*}{ Life stages } & \multicolumn{3}{|c|}{$\begin{array}{l}\text { Shannon Index } \\
\left(H^{\prime}\right)\end{array}$} & \multicolumn{3}{|c|}{$\begin{array}{l}\text { Shannon } \\
\text { evenness (E) }\end{array}$} & \multicolumn{3}{|c|}{$\begin{array}{l}\text { Rarefaction } \\
\text { (no. of OTUs) }\end{array}$} & \multicolumn{3}{|c|}{$\begin{array}{l}\text { Chao1 (no. of } \\
\text { OTUs) }\end{array}$} & \multicolumn{3}{|c|}{ Coverage (\%) } \\
\hline & & $3 \%$ & $5 \%$ & $20 \%$ & $3 \%$ & $5 \%$ & $20 \%$ & $3 \%$ & $5 \%$ & $20 \%$ & $3 \%$ & $5 \%$ & $20 \%$ & $3 \%$ & $5 \%$ & $20 \%$ \\
\hline \multicolumn{17}{|c|}{ Lucilia cuprina } \\
\hline & G1egg & 4.45 & 3.62 & 1.53 & 0.80 & 0.74 & 0.51 & 253 & 133 & 20 & 346 & 164 & 27 & 73 & 81 & 74 \\
\hline & Larva & 3.64 & 3.05 & 1.16 & 0.70 & 0.66 & 0.45 & 187 & 104 & 13 & 269 & 124 & 13 & 70 & 84 & 98 \\
\hline & Pupa & 4.08 & 3.20 & 1.55 & 0.74 & 0.66 & 0.52 & 241 & 131 & 20 & 371 & 197 & 27 & 65 & 66 & 74 \\
\hline & Adult (Male) & 3.82 & 2.88 & 1.52 & 0.71 & 0.62 & 0.53 & 224 & 108 & 18 & 321 & 139 & 18 & 70 & 78 & 100 \\
\hline & Adult (F & 4.45 & 3.43 & 1.16 & 0.75 & 0.66 & 0.47 & 378 & 174 & 12 & 526 & 215 & 12 & 72 & 81 & 100 \\
\hline & G2egg & 4.13 & 3.85 & 2.69 & 0.93 & 0.92 & 0.93 & 84 & 66 & 18 & 134 & 116 & 18 & 62 & 57 & 100 \\
\hline \multicolumn{17}{|c|}{ Lucilia sericata } \\
\hline & G1egg & 3.65 & 2.86 & 1.06 & 0.66 & 0.60 & 0.38 & 243 & 119 & 16 & 390 & 152 & 16 & 62 & 78 & 100 \\
\hline & Larva & 3.58 & 2.46 & 1.22 & 0.66 & 0.52 & 0.48 & 235 & 110 & 13 & 326 & 134 & 16 & 72 & 82 & 81 \\
\hline & Pupa & 4.17 & 3.39 & 1.96 & 0.77 & 0.69 & 0.64 & 225 & 136 & 21 & 383 & 262 & 21 & 59 & 52 & 100 \\
\hline & Adult (Male) & 2.45 & 1.18 & 0.26 & 0.52 & 0.30 & 0.11 & 111 & 48 & 11 & 158 & 67 & 12 & 70 & 71 & 92 \\
\hline & Adult (Female) & 4.17 & 2.87 & 0.89 & 0.75 & 0.62 & 0.35 & 250 & 103 & 13 & 348 & 132 & 14 & 72 & 78 & 96 \\
\hline & G2egg & 3.80 & 3.30 & 2.12 & 0.88 & 0.84 & 0.75 & 74 & 51 & 17 & 96 & 59 & 17 & 77 & 86 & 98 \\
\hline
\end{tabular}



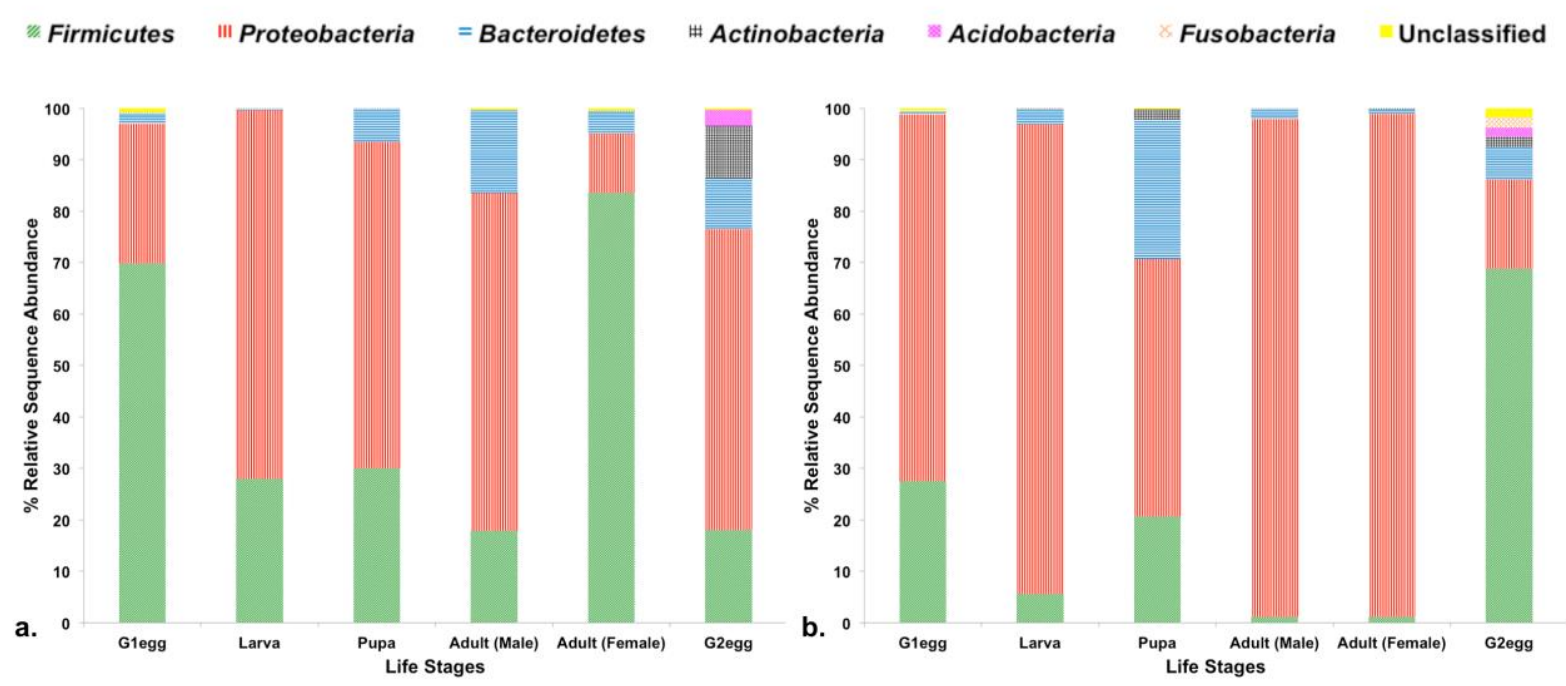

Fig. 1 Phylum level bacterial sequence diversity from successive life stages of a.) Lucilia cuprina, and b.) Lucilia sericata. G1egg indicate first generation eggs and G2egg indicate second generation eggs.

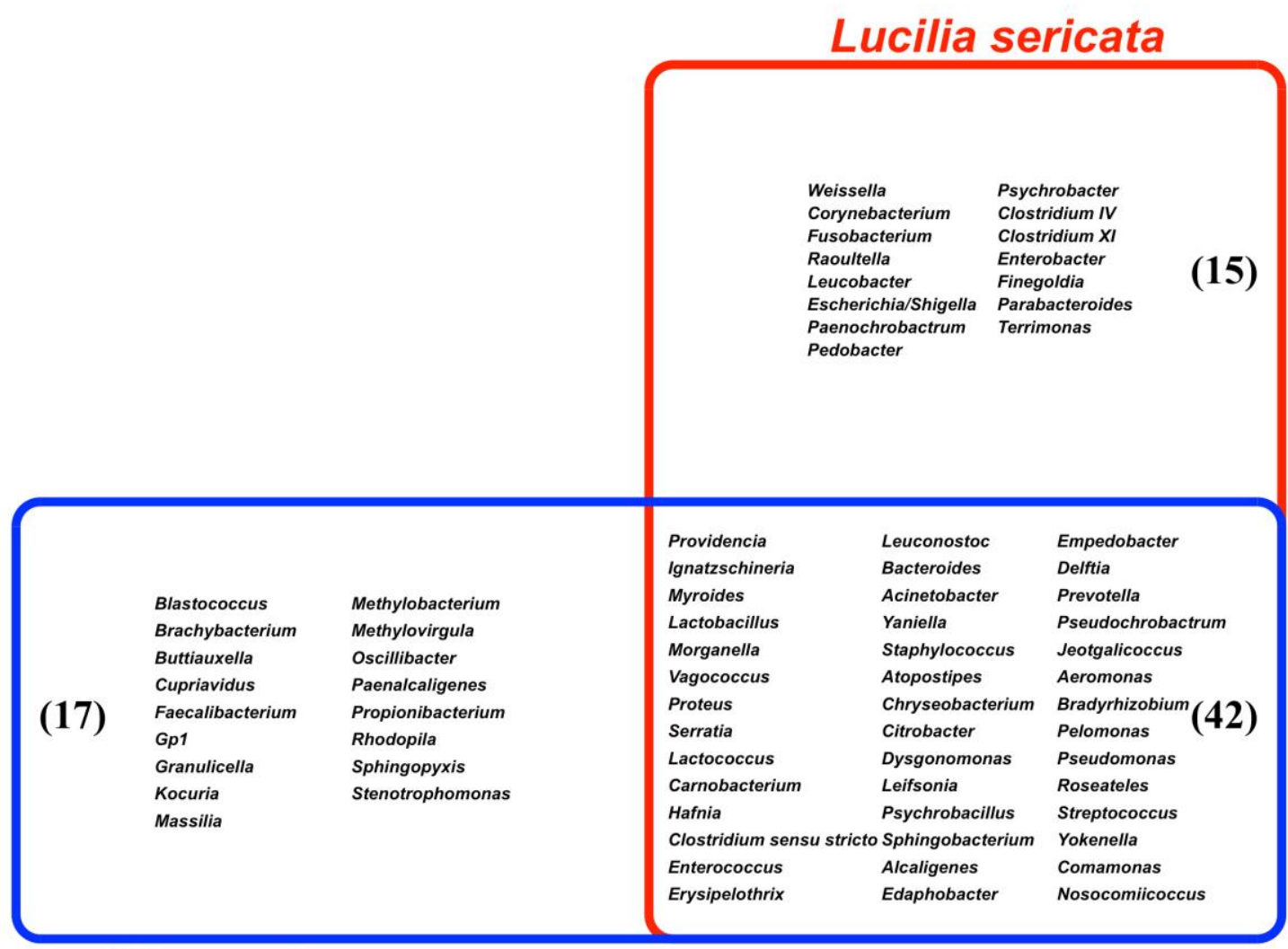

\section{Lucilia cuprina}

Fig. 2 Venn diagram of bacterial genera associated with successive life stages of Lucilia cuprina (blue rectangle) and Lucilia sericata (red rectangle). Numbers in parentheses indicate total number of unique/shared bacteria associated with each species. Venn diagram was created using program Vennture (Martin et al. 2012). 

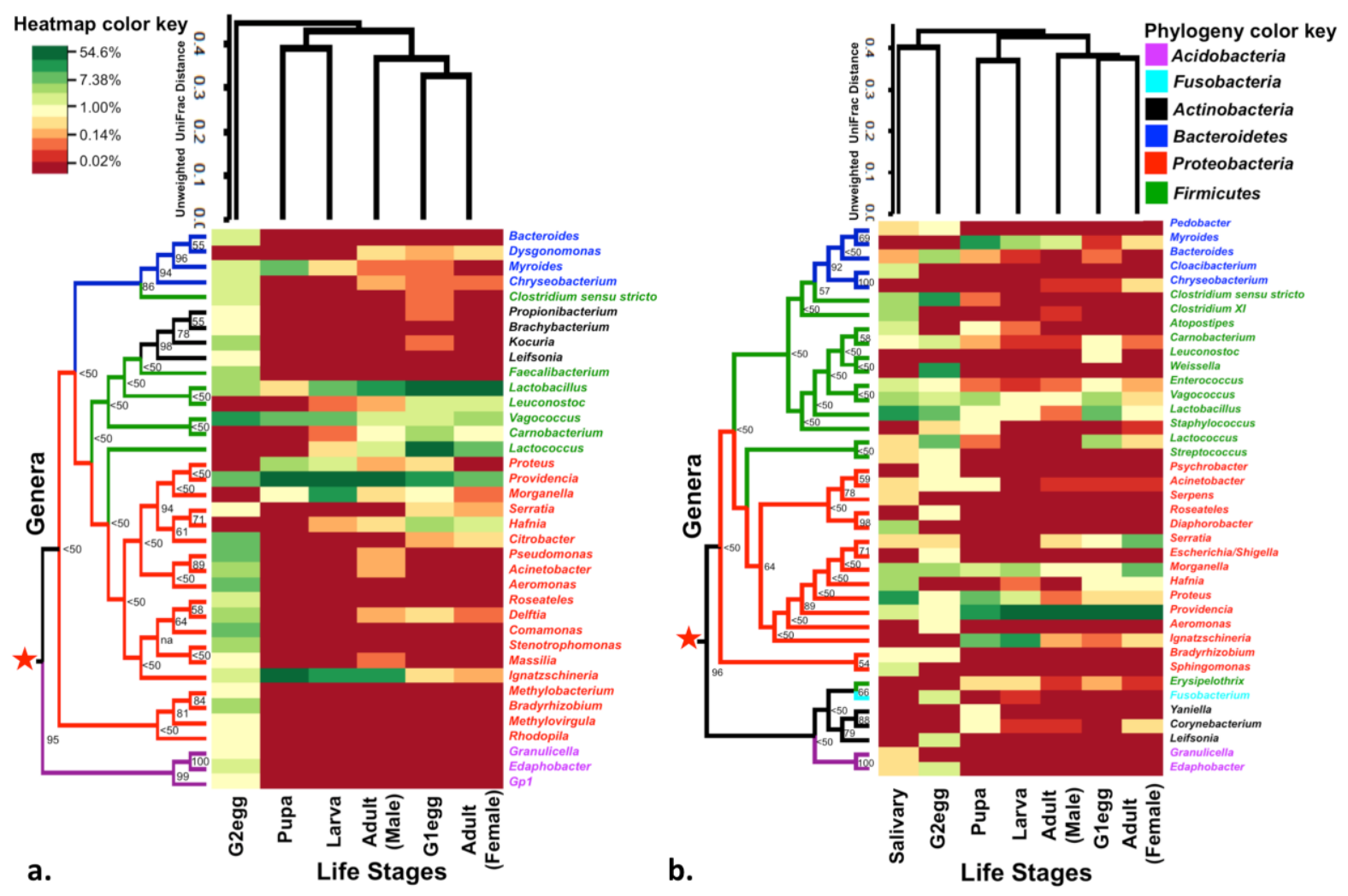

Fig. 3 Heatmap of dominant bacterial genera ( $\%$ relative sequence abundance $\geq 0.5$ ) associated with different life stages of a.) Lucilia cuprina, and b.) Lucilia sericata. Heatmap rows were clustered based on bootstrap neighbor-joining (NJ) tree of dominant genera associated with $L$. cuprina and $L$. sericata, and heatmap columns were clustered based on unweighted UniFrac distance of successive life stages of $L$. cuprina and L. sericata. For comparison purpose, $\%$ relative sequence abundance of salivary gland sample was also included along with successive life stages of $L$. sericata. $\mathrm{AM}=$ adult male; $\mathrm{AF}=$ adult female; G1egg= first generation eggs; G2egg= second generation eggs. 


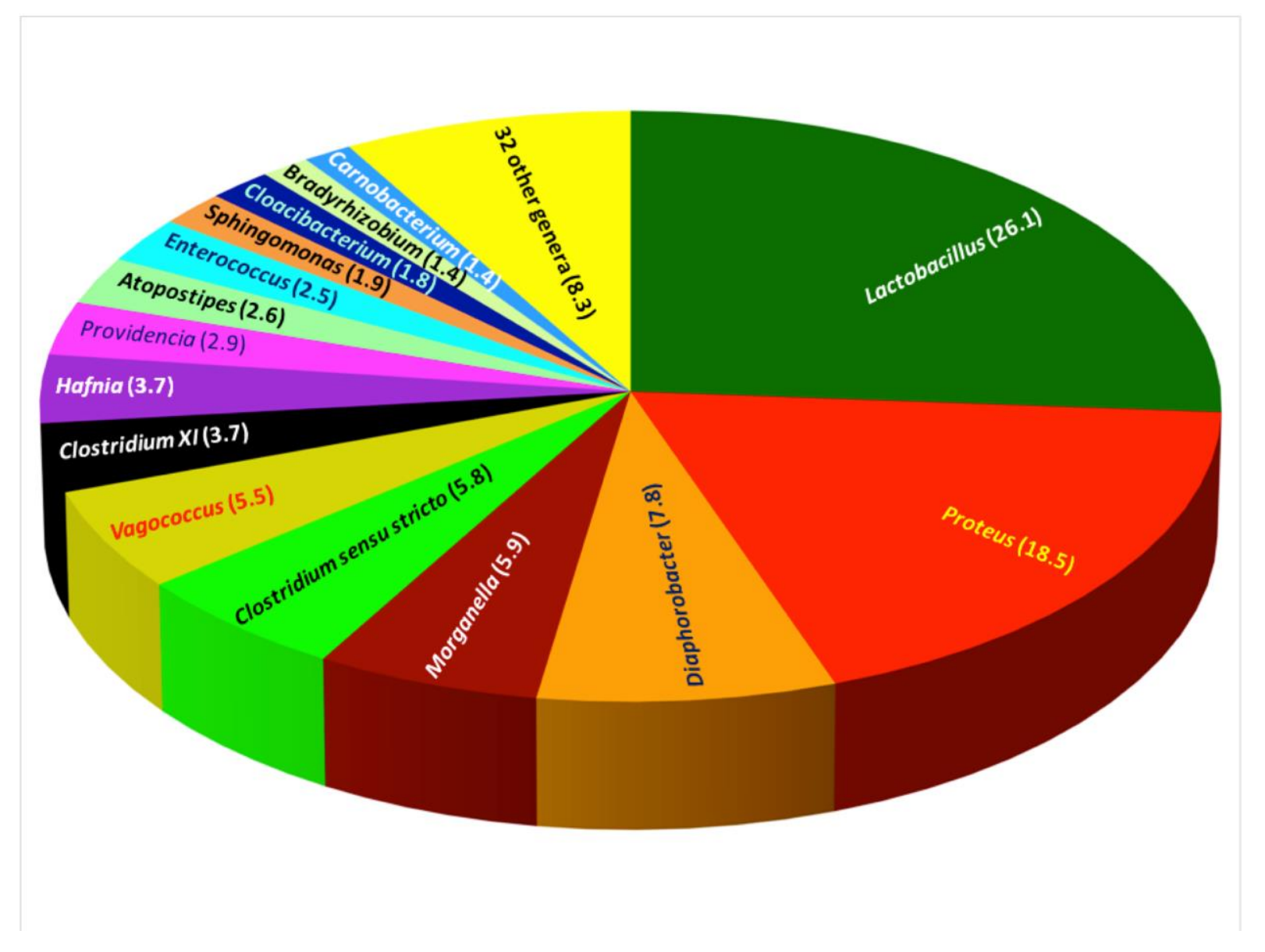

Fig. 4 Pie diagram of classified bacterial genera associated with Lucilia sericata salivary gland. Numbers in parentheses indicate percent relative sequence abundance of each genus. 
a)

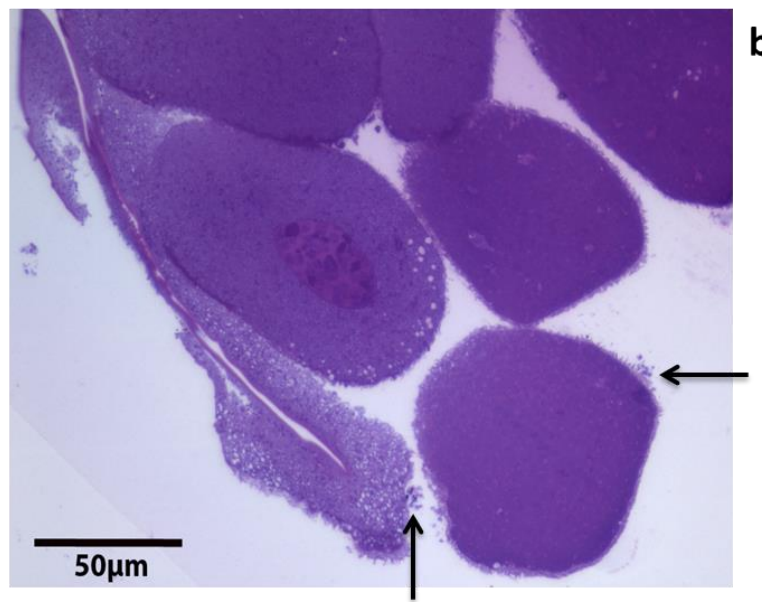

b)

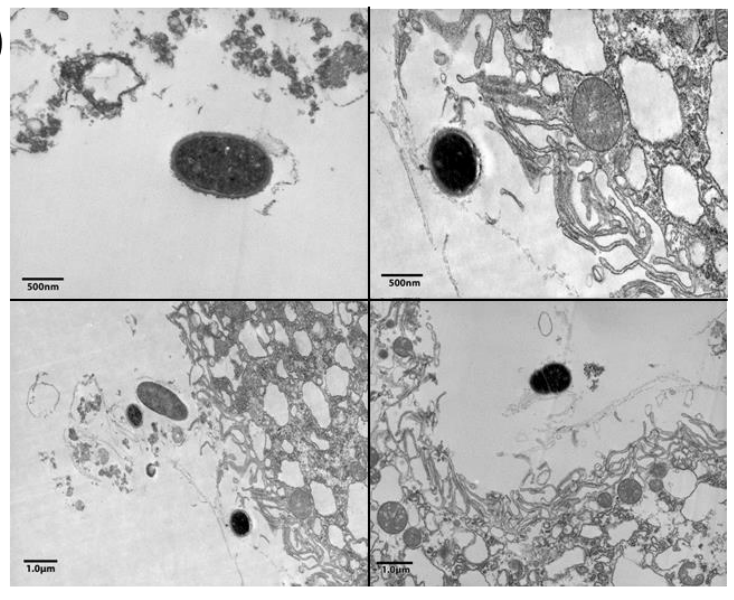

c)

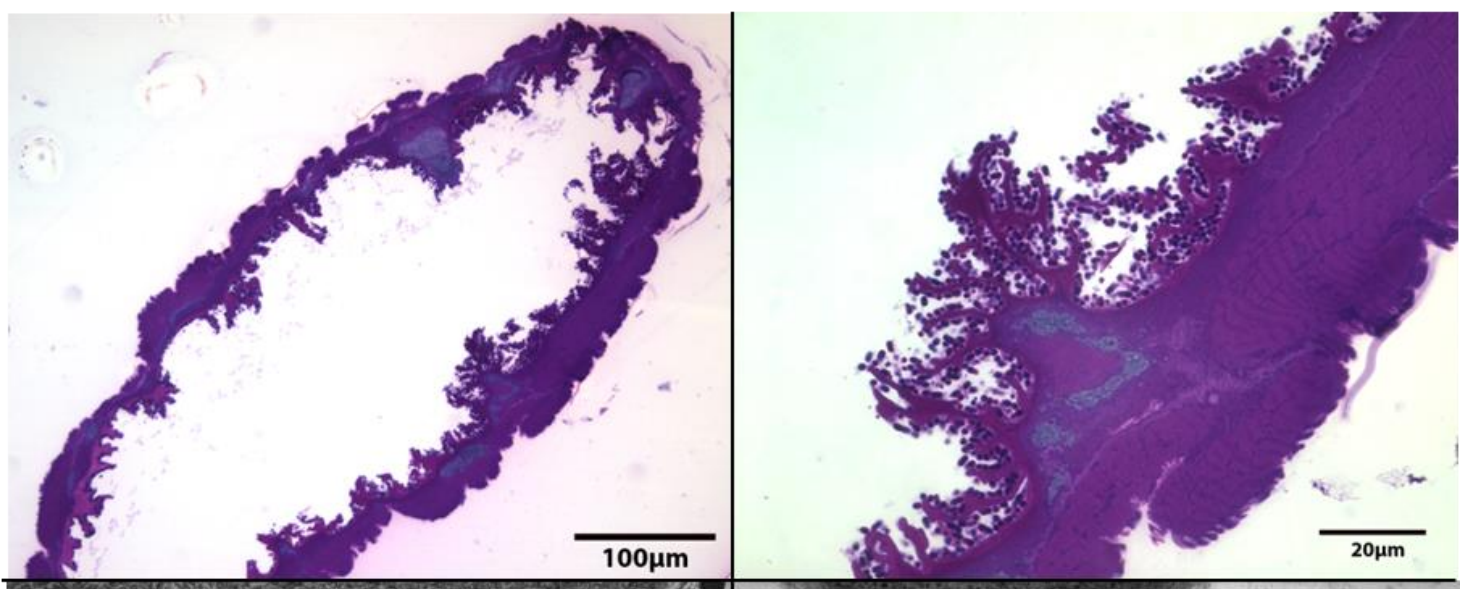

d)

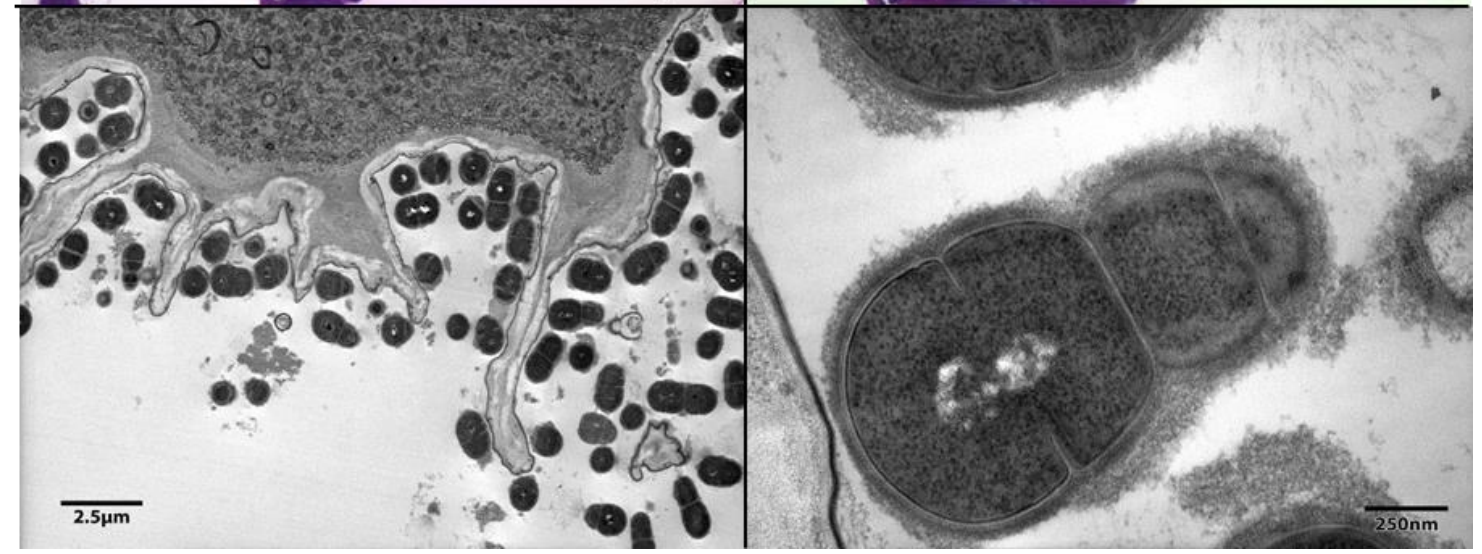

Fig. 5 Salivary gland and crop images from third instar larvae of Lucilia sericata showing morphologies suggestive of Gram positive and Gram negative bacteria (arrows) a.) Light microscopy of $750 \mathrm{~nm}$ section of salivary gland (note that bacteria were found within the lumen of the gland, and not within the salivary cells themselves), b.) Transmission electron microscopy (TEM) of $70 \mathrm{~nm}$ section of salivary gland, c.) Light microscopy of $750 \mathrm{~nm}$ section of crop and d.) Transmission electron microscopy (TEM) of $70 \mathrm{~nm}$ section of crop. TEM sections were viewed in a Hitachi H7000 transmission electron microscope. Scale bars are shown. 

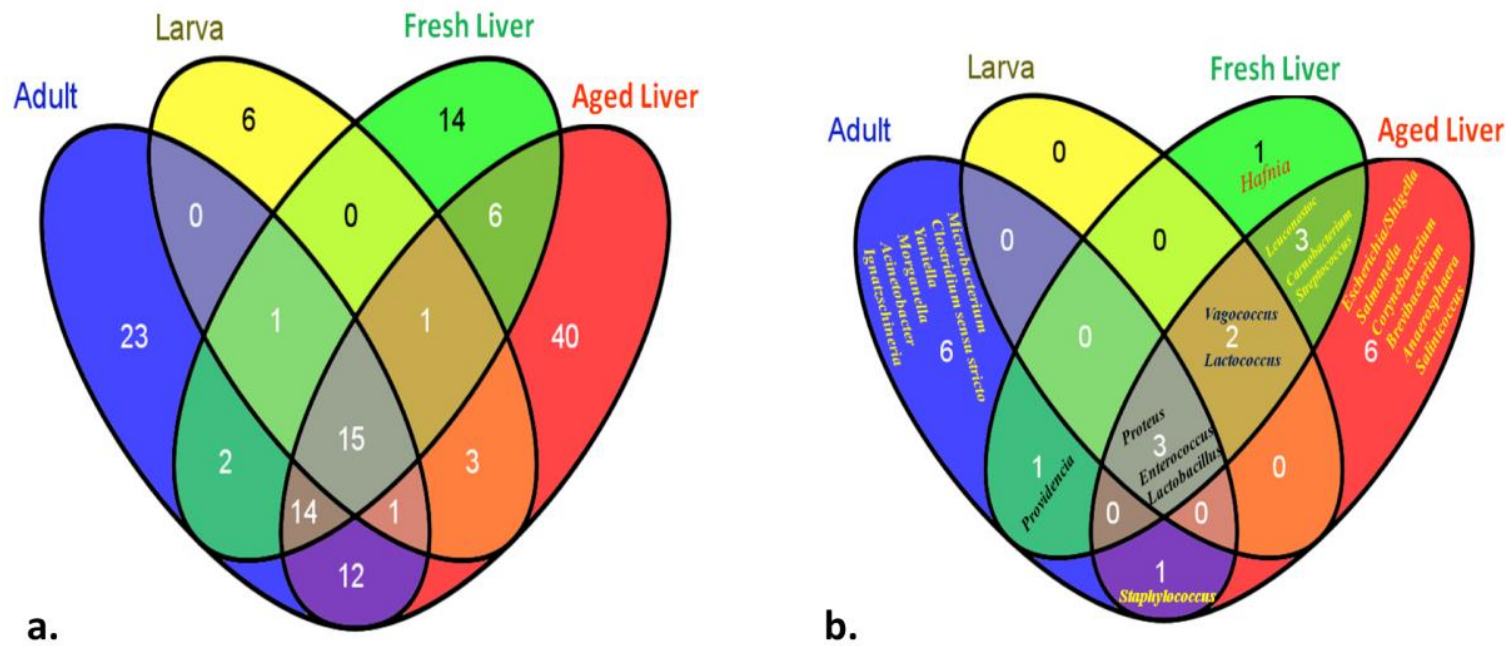

Fig. 6 Venn diagram of a.) all bacterial genera, and b.) bacterial genera that were present at $0.5 \%$ or higher relative abundance, associated with Lucilia sericata adult, Lucilia sericata larvae, fresh liver, and aged liver. Numbers indicate total number of unique and shared bacteria. Venn diagrams were created using web based program Venny (http://bioinfogp.cnb.csic.es/tools/venny/). 


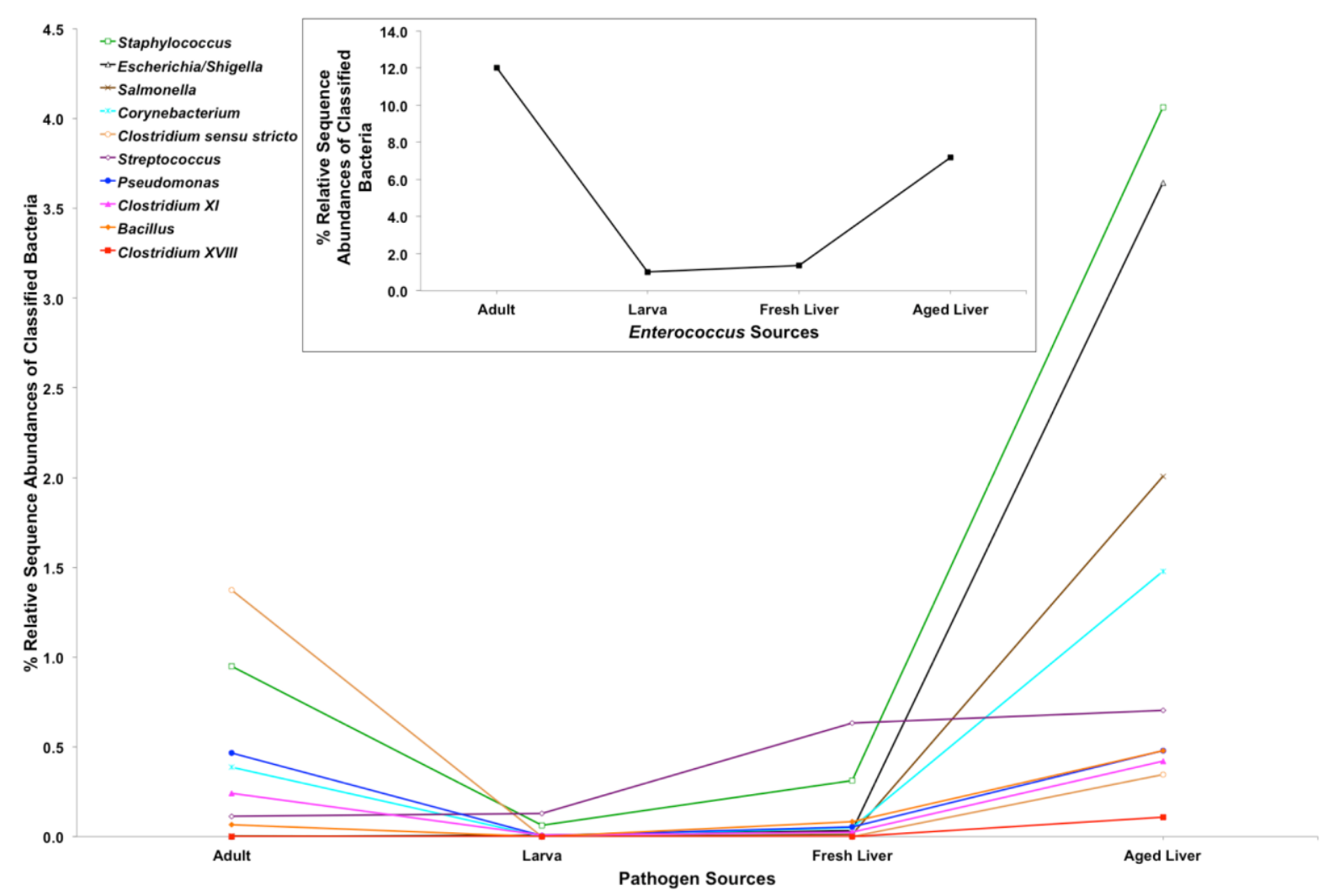

Fig. 7 Line graph showing transmission of pathogenic bacteria. Graph in inset shows transmission of Enterococcus. Relative abundances of these bacteria were obtained from 454sequences using RDP classifier. 